Revista Eletrônica de Direito Processual - REDP.

Rio de Janeiro. Ano 16. Volume 23. Número 1. Janeiro a Abril de 2022

Periódico Quadrimestral da Pós-Graduação Stricto Sensu em Direito Processual da UERJ

Patrono: José Carlos Barbosa Moreira (in mem.). ISSN 1982-7636. pp. 1160-1187 www.redp.uerj.br

\title{
STANDARDS PROBATÓRIOS NO MANDADO DE SEGURANÇA - CRITÉRIOS PARA APRECIAÇÃO DA VERDADE ${ }^{1}$
}

\section{QUANTUM OF PROOF IN THE WRIT OF MANDAMUS - CRITERIA FOR ASSESSING THE TRUTH}

Rafael Diogo Diógenes Lemos Mestre em Direito (Universidade Federal do Rio Grande do Norte). Doutorando em Direito Constitucional (Universidade de Fortaleza). Professor do Centro Universitário Estácio de Sá/CE. Procurador do Município de Londrina. Londrina/PR. E-mail: rafael.diogo@gmail.com.

Vicente de Paulo Augusto Oliveira Júnior Doutor em Direito Constitucional Público e Teoria Política (UNIFOR). Pós-Doutorando em Direito Constitucional (UNIFOR). Professor do curso de Direito do Centro Universitário Fanor Wyden (UniFanor Wyden). Coordenador do Grupo de Estudos e Pesquisas em Direito Administrativo e Tributário (GEPDAT). Fortaleza/CE. E-mail: vicenteaugusto2@gmail.com.

RESUMO: Neste trabalho, será analisada a importância dos standards probatórios e sua contribuição com a racionalidade e objetividade das decisões judiciais. Serão verificados critérios para formação de um standard de prova e a necessária contextualização deste critério com aspectos metodológicos, epistemológicos, jurídicos e políticos. Buscar-se-á, de modo mais objetivo, analisar os standards exigidos no mandado de segurança, dada sua peculiaridade procedimental e probatória. Debate-se, também, os critérios e padrões na busca pela verdade no

\footnotetext{
${ }^{1}$ Artigo recebido em 19/07/2021 e aprovado em 10/12/2021.
} 
Revista Eletrônica de Direito Processual - REDP.

Rio de Janeiro. Ano 16. Volume 23. Número 1. Janeiro a Abril de 2022

Periódico Quadrimestral da Pós-Graduação Stricto Sensu em Direito Processual da UERJ

Patrono: José Carlos Barbosa Moreira (in mem.). ISSN 1982-7636. pp. 1160-1187

www.redp.uerj.br

processo e em que ponto fatores não-epistemológicos" influenciam na busca pela verdade no processo.

ABSTRACT: In this paper, the importance ofstandards of proof and their role to the rationality and objectivity of judicial decisions will be analyzed. Criteria for the formation of a standard of proof and the necessary contextualization of this criterion with methodological, epistemological, legal and political aspects will be verified. The paper will aim, in a more objective way, to analyze the standards required in the writ of mandamus, given its procedural and evidential peculiarity. The criteria and standards in assessng truth in the process are also debated and at what point non-epistemological factors influence the search for truth in the process

PALAVRAS-CHAVE: Standards probatórios; verdade; mandado de segurança; racionalidade.

KEYWORDS: Quantum of proof; truth; writ of mandamus; rationality.

\section{INTRODUÇÃO}

A busca por um padrão decisório constitui em exigência epistemológica no processo, legitimando-o por meio da verdade e permitindo que o direito alcance seus fins de regulação de condutas sociais. Com a racionalidade inerente ao processo, é necessário que todas as etapas sejam sujeitas a controles inter-subjetivos, em especial a última etapa do processo, qual seja, a decisão judicial.

A despeito desta exigência racional, a busca pela verdade no processo carece de critérios racionais, sendo construída, muitas vezes, com base em padrões subjetivos do julgador. As evoluções no processo no tocante ao direito probatório constroem padrões objetivos de escolha dos fatos a serem provados, valoração da prova e, em especial, padrões de julgamento.

O objeto do presente estudo é investigar o critério de verdade utilizado no mandado de segurança e os meios de se atingir esta verdade. Debater-se-á qual o padrão de verdade 
Revista Eletrônica de Direito Processual - REDP.

Rio de Janeiro. Ano 16. Volume 23. Número 1. Janeiro a Abril de 2022

Periódico Quadrimestral da Pós-Graduação Stricto Sensu em Direito Processual da UERJ

Patrono: José Carlos Barbosa Moreira (in mem.). ISSN 1982-7636. pp. 1160-1187 www.redp.uerj.br

necessário à concessão de uma decisão judicial e quais os critérios metodológicos, epistemológicos, judiciais e políticos para a formação destes critérios.

Ademais, buscar-se-á analisar o papel dos standards probatórios, em especial na objetivação da formação da verdade pelo magistrado, enquanto instrumento de racionalidade do processo. Em verdade, dada a necessária racionalidade do processo, é preciso permitir que todos os seus atos sejam verificáveis e sujeitos a testes de falseabilidade, ampliando o controle pelas partes, pela sociedade e pelo próprio Poder Judiciário por meio de critérios intersubjetivos e racionais.

Buscar-se-á, mais especificamente, analisar o quantum probatório no mandado de segurança, dada peculiaridades procedimentais e probatórias nesta ação de natureza constitucional. Verificar-se-á em que ponto a lei reduz (ou não) os meios de prova do magistrado e qual o padrão exigido do magistrado para que seja alcançada a verdade e concedida a segurança.

\section{A VERDADE E A PROVA NO PROCESSO}

O processo judicial é o locus estatal por excelência para a obtenção de verdade, de modo a se obter uma resposta jurisdicional de solução definitiva de uma lide. O critério de verdade a ser utilizado no processo, todavia, é bastante debatido, sendo comum aqueles que a dividem entre "verdade material" e "verdade formal", sendo apenas esta alcançável pelo processo.

Vale dizer que se parte de um subjetivismo processual, levando-se em consideração a existência de três "verdades": a verdade apresentada pelo autor, a verdade defendida pelo réu e, por último, aquela atingida pelo Estado-juiz. Este subjetivismo varia a depender de aspectos políticos os mais variados, sendo maior ou menor a exigência desta "verdade formal", quando se estiver frente a, por exemplo, direitos materiais de maior ou menor envergadura (exigência de uma verdade mais "qualificada" no âmbito do processo penal do que no âmbito do processo civil, por exemplo) ou se estiver frente a procedimentos sumarizados ou ordinários (concessão de decisão em ações possessórias com natureza de tutela provisória de evidência).

2 MARINONI, Luiz Guilherme, ARENHART, Sergio Cruz, MITIDIERO, Daniel. Curso de Processo Civil: Volume 2. 4 ed. São Paulo: Revista dos Tribunais, 2018. p. 255. 
Revista Eletrônica de Direito Processual - REDP.

Rio de Janeiro. Ano 16. Volume 23. Número 1. Janeiro a Abril de 2022

Periódico Quadrimestral da Pós-Graduação Stricto Sensu em Direito Processual da UERJ

Patrono: José Carlos Barbosa Moreira (in mem.). ISSN 1982-7636. pp. 1160-1187

www.redp.uerj.br

A verdade no processo, contudo, é aquela processual ${ }^{3}$, não se confundindo com a material, conforme explicitar-se-á ao longo deste texto. Isso significa que o objetivo do processo que é a busca da verdade a alcançará por meio de fatos intermediados que serão denominados provas (assim, a prova testemunhal é uma "verdade" intermediada pelo relato de uma pessoa; a prova documental é uma "verdade" intermediada por um documento produzido pelas partes ou por terceiros; a prova pericial é uma "verdade" produzida por um expert de confiança do juiz ou das partes que emitirá um parecer sobre a questão a ser decidida, com imparcialidade) e estas provas, submetidas ao contraditório, conduzirão o magistrado a alcançar a verdade processual que será o substrato da decisão judicial.

Tem-se, portanto, uma adoção de um conceito autopoiético do direito; os fatos apenas serão relevantes ao Direito enquanto forem incluídos no processo por intermediação das provas, obedecendo a critérios legais rigorosos previamente definidos, desconsiderando-se qualquer fato não internalizado segundo a linguagem própria do Direito.

Após a escolha do material a ser provado, da valoração da prova e, ao final, do julgamento com base nas provas apresentadas - etapas de escolha, valoração e julgamento que serão apresentadas nos próximos tópicos - o magistrado estará de frente a um material "bruto", cabendo a ele decidir se aquele material será ou não suficiente para a prolação de uma decisão judicial, bem como se aquelas provas levarão a uma decisão que beneficiará o réu ou o autor. Vale dizer, face ao non liquet, que proíbe o juiz de não proferir decisões em um processo judicial, deverá este escolher, frente ao material que lhe é apresentado, se foi ou não alcançada a "verdade" e se as partes cumpriram ou não seu ônus probatório. Após esta etapa, o juiz poderá emitir uma decisão judicial, apontando a "sua" verdade.

Esta etapa de julgamento não é (não pode ser) completamente subjetivista, devendo haver certos padrões mínimos para que o magistrado considere ou não provada uma alegação. Estes padrões são denominados standards probatórios, que serão maiores ou menores a depender de alguns fatores políticos explicitados na legislação. A parametrização do processo decisório por meio de níveis probatórios é um método de redução do subjetivismo e, por

${ }^{3}$ FÉRRER-BELTRAN, Jordi. Valoração racional da prova. Trad. Vitor de Paulo Ramos. Salvador: Juspodivm, 2021.p. 45 
Revista Eletrônica de Direito Processual - REDP.

Rio de Janeiro. Ano 16. Volume 23. Número 1. Janeiro a Abril de 2022

Periódico Quadrimestral da Pós-Graduação Stricto Sensu em Direito Processual da UERJ

Patrono: José Carlos Barbosa Moreira (in mem.). ISSN 1982-7636. pp. 1160-1187 www.redp.uerj.br

conseguinte, de possibilitar um maior controle da sociedade e das próprias partes sobre o processo, avaliando de forma racional o iter percorrido e o critério utilizado pelo juiz ao apreciar uma prova produzida em processo.

Assim, a verdade no Direito não é subjetiva ou objetiva ${ }^{4}$, mas processual e, em razão disso, estará sujeita a alguns padrões epistemológicos e jurídicos que serão discutidos ao longo deste estudo.

\subsection{Conceito da verdade no processo}

O debate filosófico sobre a verdade traz diversos pontos de vista, com questionamentos que os seus defensores buscam respondê-los de variadas formas a depender da teoria adotada. Para os subjetivistas, a verdade está centrada no sujeito cognoscente, de modo que depende deste partir para a análise do objeto e, portanto, poderá variar de acordo com o indivíduo. Já os objetivistas, por seu turno, acreditam que a verdade está centrada no objeto e esta apenas será revelada para o sujeito cognoscente que a buscar. Assim, a verdade seria uma, absoluta e apenas seria descortinada para o investigador. ${ }^{5}$

No âmbito jurídico, um de seus principais objetivos é a busca da verdade. De fato, ao entendermos o Direito como uma ciência social aplicada que busca a solucionar problemas jurídicos reais, a busca da verdade deve pautar toda a atuação do Direito e, em especial, do processo. Assim, o Direito deve também se preocupar de que modo alcançará a verdade de um fato posto à sua apreciação para que possa aplicar corretamente as consequências previstas no ordenamento jurídico.

A busca da verdade, no Direito, seria uma busca pragmática, no sentido de que intenta resolver um caso concreto. Não se descuida de fatores epistêmicos de busca da verdade, mas deve se preocupar com outros fatores - limitações jurídicas, fatores extrajurídicos como tempo e custos - para alcançar-se uma verdade possível na situação. Cabe aos aplicadores do direito,

\footnotetext{
${ }^{4}$ HESSEN, Johannes. Teoria do Conhecimento. Trad.: João Vergílio Gallerani Cuter. São Paulo: Martins Fontes, 2003.p. 70

${ }^{5}$ Idem, ibidem.
} 
Revista Eletrônica de Direito Processual - REDP.

Rio de Janeiro. Ano 16. Volume 23. Número 1. Janeiro a Abril de 2022

Periódico Quadrimestral da Pós-Graduação Stricto Sensu em Direito Processual da UERJ

Patrono: José Carlos Barbosa Moreira (in mem.). ISSN 1982-7636. pp. 1160-1187 www.redp.uerj.br

portanto, elaborar um raciocínio indutivo em que partirão de uma situação concreta (fato apreciável) para uma solução geral (norma) e utilizar métodos que revelem esta verdade.

O Direito, assim, se preocupa com o processo de apreensão do conhecimento para a busca da verdade, razão pela qual o procedimento probatório no âmbito processual é sempre descrito com muita acurácia. São diversas normas escritas, detalhando de modo rigoroso como são realizadas as provas, quais provas admitidas e como valorar as provas obtidas em um determinado caso. O Direito se preocupa, portanto, com três etapas da produção da prova que formarão o iter entre o sujeito cognoscente e o objeto a ser conhecido: a formação do conjunto de elementos de prova, valoração das provas obtidas e o julgamento sobre elas. ${ }^{6}$

Ainda há mais algumas particularidades que devem ser ditas com relação à busca da verdade no processo.

De início, há três verdades no processo, cada qual tentando influenciar as demais. Embora a decisão processual seja elaborada somente por um de seus participantes, tanto demandante quanto demandado intervém (ou, pelo menos, têm a condição de intervir) para a formação da decisão e, por conseguinte, no processo de descoberta da verdade. As partes tratam de delimitar a abrangência da busca da verdade, apontando os fatos que serão litigiosos, bem como as provas a serem apresentadas. Não há impedimento para que o demandante, por exemplo, deixe de fora aspecto fático importante para a busca da verdade; da mesma forma, não há óbice para que o demandado, expressa ou tacitamente, consinta sobre os fatos apresentados e, dessa forma, a busca da verdade será determinada pela exposição realizada somente pelo autor no processo. Não é custoso imaginar que, muitas vezes, se obtém uma resposta epistemologicamente falsa, mas processualmente correta em razão destas limitações.

Em razão desta possível abrangência da busca da verdade no processo, não se pode descuidar que, pelo seu caráter pragmático, o fator temporal limita a atuação dos atores processuais na busca da verdade. Os modernos sistemas jurídicos elencam a razoável duração do processo como um dos elementos indissociáveis à prestação da jurisdição. O ordenamento

${ }^{6}$ FÉRRER-BELTRAN, Jordi. op. cit. p. 62. 
Revista Eletrônica de Direito Processual - REDP.

Rio de Janeiro. Ano 16. Volume 23. Número 1. Janeiro a Abril de 2022

Periódico Quadrimestral da Pós-Graduação Stricto Sensu em Direito Processual da UERJ

Patrono: José Carlos Barbosa Moreira (in mem.). ISSN 1982-7636. pp. 1160-1187

www.redp.uerj.br

jurídico brasileiro não é diferente ao prevê-la como direito fundamental no artigo $5^{\circ}$, LXXVIII, da Constituição da República Federativa do Brasil. ${ }^{7}$

Como outro ponto importante, a "verdade" obtida no processo adquirirá o atributo da definitividade, não podendo ser alterada ou apenas podendo sofrer alterações em raras hipóteses de ações rescisórias ou ações de querela nullitatis insanabilis. Assim, a falibilidade do conhecimento humano, de que falava Popper, não é aplicada de forma absoluta ao contexto jurídico, especialmente após a solução de um caso específico em um processo judicial (ou administrativo, a depender do sistema jurídico). É importante fazer a distinção neste ponto, pois Popper apontava que o conhecimento indutivo era falível e, sendo a lógica processual uma lógica indutiva, esta também seria falível e, portanto, mutável. Apontava Popper ${ }^{8}$ :

Ora, está longe de ser óbvio, de um ponto de vista lógico, haver justificativa no inferir enunciados universais de enunciados singulares, independente de quão numerosos sejam estes; com efeito, qualquer conclusão colhida desse modo sempre pode revelar-se falsa: independentemente de quantos cisnes brancos possamos observar, isso não justifica a conclusão de que todos os cisnes são brancos. A questão de saber se as inferências indutivas se justificam e emque condições é conhecida como o problema da indução.

Com isso, avultam os três momentos da atividade de produção da prova: formação do conjunto de elementos a serem provados, valoração da prova e seu julgamento. A compreensão destas etapas mostra-se como um elemento necessário à concepção de verdade em um ambiente que não tolera erros (ou, na verdade, que não erra, uma vez que a verdade obtida passa a ser imutável), que conta com participação ativa de múltiplos sujeitos cognoscentes e que conta com fatores "não-epistemológicos" importantes, como o fator econômico e o fator temporal.

A primeira etapa, para Ferrer-Beltrán consiste no "subconjunto formado pela totalidade dos elementos disponíveis: aqueles que foram incorporados aos autos judiciais"9. Esta etapa leva em consideração a participação das partes - em geral, cabe aos sujeitos parciais no processo

\footnotetext{
${ }^{7}$ Art. $5^{\circ}$. (omissis)

LXXVIII - a todos, no âmbito judicial e administrativo, são assegurados a razoável duração do processo e os meios que garantam a celeridade na sua tramitação

${ }^{8}$ POPPER, Karl. A Lógica da pesquisa científica. Trad. Leonidas Hegenberg e Octanny Silveira da Mota. Cultrix: São Paulo, 2008.p. 27-28

${ }^{9}$ FÉRRER-BELTRAN, Jordi,. op. cit., p. 63.
} 
Revista Eletrônica de Direito Processual - REDP.

Rio de Janeiro. Ano 16. Volume 23. Número 1. Janeiro a Abril de 2022

Periódico Quadrimestral da Pós-Graduação Stricto Sensu em Direito Processual da UERJ

Patrono: José Carlos Barbosa Moreira (in mem.). ISSN 1982-7636. pp. 1160-1187

www.redp.uerj.br

definirem os fatos controvertidos que demandarão prova e as provas aptas a comprovarem suas alegações - bem como o conjunto de fatos e provas levadas ao processo. Este conjunto de fatos pode ou não coincidir com todos os fatos "reais"10, seja por livre escolha das partes de não alegar algo, seja porque as partes simulam um processo com finalidades escusas. Assim, é plenamente possível obter uma "verdade" no âmbito do processo que não tenha nenhuma (ou mínima) relação com a verdade "real", mas, estando de acordo com as provas obtidas no processo, será admitida esta relação.

A segunda etapa é a valoração dos elementos de prova pelo juízo. Neste ponto, poderemos ter um sistema de livre admissão de meios de prova pelo juízo ou mesmo um sistema legal de provas - como ocorre com o mandado de segurança, por exemplo - que previamente exclui um (ou vários) meios de prova que, em tese, seriam admissíveis. A etapa de valoração consiste em uma etapa de inclusão/exclusão, permitindo-se, portanto, uma maior ou menor possibilidade de provar a alegação, a depender de fatores políticos.

A segunda etapa é, normalmente, determinada por critérios políticos, fato que também se repetirá na terceira etapa. Assim, é comum que em processos que buscam aplicar a lei penal, cujo bem da vida perseguido é de alta importância, sejam admitidos todos os tipos de prova. Tem-se uma regra de inclusão ampliada, portanto. Em processos de outra natureza, como sói de ocorrer no processo previdenciário $^{11}$, por exemplo, podem ser excluídos previamente algum(ns)

${ }^{10}$ Taruffo aponta que no contexto processual, é necessário "adoptar um concepto de verdade como correspondência de las proposiciones relativas a los hechos de la causa con la realidad empírica de tales hechos." TARUFFO, Michele. La verdade en el proceso. Trad. Eugenia Ariano Deho. In Revista Derecho \& Sociedad 40. Pp. 239-248. Disponível em:< https://www.google.com/url?sa=t\&rct=j\&q=\&esrc=s\&source=web\&cd=\&ved=2ahUKEwj_oaWR98HvAhWCJb kGHcQFDzUQFjAAegQIARAD\&url=http\%3A\%2F\%2Frevistas.pucp.edu.pe\%2Findex.php\%2Fderechoysocied ad\%2Farticle\%2Fdownload\%2F12804\%2F13361\%2F0\&usg=AOvVaw2Qxb7olXCCUcUIp9uu7q2T>. Acesso em: 19 mar. 2021

${ }^{11}$ Como exemplo, artigo $16, \S 5^{\circ}$, da Lei 8.212/1991 que determina que a prova da união estável deverá conter, pelo menos, início de prova material (ou seja, documental), e ainda tecendo critério cronológico de exclusão (prova produzida com até 24 meses), não se admitindo qualquer outro meio de comprovação se não fundamentada com documento.

Art. 16 - omissis

$\S 5^{\circ}$ - As provas de união estável e de dependência econômica exigem início de prova material contemporânea dos fatos, produzido em período não superior a 24 (vinte e quatro) meses anterior à data do óbito ou do recolhimento à prisão do segurado, não admitida a prova exclusivamente testemunhal, exceto na ocorrência de motivo de força maior ou caso fortuito, conforme disposto no regulamento. 
Revista Eletrônica de Direito Processual - REDP.

Rio de Janeiro. Ano 16. Volume 23. Número 1. Janeiro a Abril de 2022

Periódico Quadrimestral da Pós-Graduação Stricto Sensu em Direito Processual da UERJ

Patrono: José Carlos Barbosa Moreira (in mem.). ISSN 1982-7636. pp. 1160-1187

www.redp.uerj.br

tipo(s) de prova, tendo-se uma regra de inclusão diminuída, restringindo, portanto, o campo de discussão no processo e, por conseguinte, o alcance da verdade.

Como derradeira etapa, tem-se o julgamento propriamente dito sobre as provas apresentadas. O juiz deverá considerar se as provas apresentadas são ou não aptas para corroborar os pedidos das partes, o que implica que haja um certo nivelamento para o critério de verdade a ser alcançada. Assim, a partir de que ponto o magistrado poderá se dar por satisfeito com as provas e decidir favoravelmente a um ou outro lado do processo?

Aqui, é comum também que haja exigências políticas distintas, a depender do bem da vida a ser buscado no processo. Em um processo penal, exige-se, em geral, um grau mais elevado para se obter a condenação; já no âmbito do processo civil é comum um critério mais brando, distribuindo-se igualmente às partes os graus de verdade. Taruffo ${ }^{12}$ resume o problema, apontando três questionamentos: (a) quando um conjunto de provas produzidas não permite extrair nenhuma conclusão sobre a verdade ou falsidade das alegações das partes; (b) quando se pode afirmar que o conjunto de provas aponte com certeza a verdade ou falsidade das alegações e, por último (c) que as provas confirmem ou neguem a realidade ou falsidade das informações, mas não em um grau necessário para conceder os pedidos realizados.

A "verdade" tratada no processo não se confunde com a "verdade material", que é aquela que "supõe a perfeita correspondência entre a realidade e a ideia que dela se faz". ${ }^{13}$ Em um sistema com várias regras de exclusão (inadmissibilidade de provas ilícitas ou imorais, por exemplo) e com vários fatores extrajurídicos limitantes (fator temporal, cronológico, participativo e possivelmente de colusão entre as partes), esta é inalcançável. Por outro lado, a verdade processual é não somente aquela mediada pelos fatores de inclusão e exclusão acima postos, mas, acima de tudo, em que se exclua (ou seja diminuída) a subjetividade do juiz, por meio da adoção de standards probatórios que serão mais ou menos exigentes a depender de critérios políticos e jurídicos. Este é o critério de verdade processual que será adotado neste estudo.

12 TARUFFO, Michele. op. cit. p. 5.

${ }^{13}$ MARINONI, Luiz Guilherme, ARENHART, Sergio Cruz, MITIDIERO, Daniel., op. cit. p. 267. 
Revista Eletrônica de Direito Processual - REDP.

Rio de Janeiro. Ano 16. Volume 23. Número 1. Janeiro a Abril de 2022

Periódico Quadrimestral da Pós-Graduação Stricto Sensu em Direito Processual da UERJ

Patrono: José Carlos Barbosa Moreira (in mem.). ISSN 1982-7636. pp. 1160-1187

www.redp.uerj.br

\section{2 $\mathrm{O}$ direito à prova como exigência da racionalidade}

Os sistemas jurídicos devem ter como um de seus principais objetivos a busca pela verdade. Enquanto conjunto de normas destinados a estimular ou desestimular a prática de determinadas condutas pela sociedade, o Direito deve investigar com precisão a prática de determinado fato para aplicar-lhe o direito cabível. Somente desta forma o Direito cumprirá a função de promover condutas. A aplicação do direito a fatos que não ocorreram (a "nãoverdade") não logra o êxito pretendido e, desta forma, deve ser evitada pelo Direito.

Para isso, é comum que os ordenamentos jurídicos regulamentem o direito de prova e os meios de exercê-lo. O momento de produção de prova, as espécies admitidas e não admitidas, procedimentos para sua produção e valoração são previsões que comumente se encontram nos diversos ordenamentos jurídicos, a depender de escolhas políticas de cada sistema processual. O direito pátrio não foge a esta regra, inclusive adotando expressamente a busca da verdade como um dos objetivos principais da produção de prova. ${ }^{14}$

No direito brasileiro, é inegável o direito fundamental à prova, atrelado que está ao contraditório, em especial à noção de contraditório substancial. Marinoni, Arenhart e Mitidiero apontam que:

Em um sistema processual, como o nacional, em que o magistrado deve convencer-se para decidir a partir das provas constantes dos autos (art. 371), é conclusão básica a de que só poderá ter sucesso uma pretensão ou uma defesa no processo - ao menos em relação a fatos - se ela estiver apoiada em provas para a sua confirmação. Por outras palavras, alegar sem provar, no processo civil brasileiro, tende a gerar a mesma consequência que sequer alegar. ${ }^{15}$

Para além de instituto de direito positivo, grafado com a pecha de fundamentalidade de direito constitucionalmente derivado, a prova é exigência racional do sistema. Vale dizer, o direito de produção de provas - e de que sejam inadmitidas, a depender de critérios escolhidos e inseridos no próprio sistema jurídico - e de valorá-las, consoante critérios jurídicos e racionais

\footnotetext{
${ }^{14}$ Código de Processo Civil, art. 369 - As partes têm o direito de empregar todos os meios legais, bem como os moralmente legítimos, ainda que não especificados neste Código, para provar a verdade dos fatos em que se funda o pedido ou a defesa e influir eficazmente na convicção do juiz.

${ }^{15}$ MARINONI, Luiz Guilherme, ARENHART, Sergio Cruz, MITIDIERO, Daniel., op. cit. p. 265.
} 
Revista Eletrônica de Direito Processual - REDP.

Rio de Janeiro. Ano 16. Volume 23. Número 1. Janeiro a Abril de 2022

Periódico Quadrimestral da Pós-Graduação Stricto Sensu em Direito Processual da UERJ

Patrono: José Carlos Barbosa Moreira (in mem.). ISSN 1982-7636. pp. 1160-1187

www.redp.uerj.br

próprios, conformam a racionalidade sistêmica que requer que as alegações produzidas sejam verificáveis para sua conformação de verdade/não-verdade.

Jordi Ferrer-Beltrán ${ }^{16}$ enuncia quatro elementos básicos que conformam o direito à prova e que são exigências, acima de tudo, epistemológicas e que, portanto, perpassam qualquer sistema jurídico específico. Vale dizer, os critérios apontados pelo autor espanhol - e adotados em sua integralidade neste texto - são exigências epistemológicas para a busca da verdade e que são incorporados de diversas formas nos mais variados sistemas jurídicos, a depender de fatores políticos, econômicos, sociais e jurídicos.

O primeiro elemento é a possibilidade de utilizar as provas a que tem acesso para demonstrar a verdade dos fatos sobre os quais se funda a pretensão ${ }^{17}$. Trata-se de uma regra de inclusão que, quanto mais ampla for utilizada no sistema jurídico, maior a compatibilidade da "verdade real" com a "verdade processual". De outro lado, quanto menor a regra de inclusão, vale dizer, quanto mais forem excluídos meios de prova, menor a adequação da "verdade real" com a "verdade processual" ou, pelo menos, menor a probabilidade de que seja alcançada.

Esta "regra de inclusão" ganha matizes diferentes em ordenamentos jurídicos diferentes ou até, em um mesmo ordenamento jurídico, a depender do objeto jurídico que se busca tutelar. Veja-se, por exemplo, a exigência no mandado de segurança que os fatos apresentados sejam documentalmente comprovados. Ou em algumas ações previdenciárias que é exigido um "início" de prova material, ou seja, que haja provas documentais a corroborar os demais meios de prova usados para fundamentar as alegações.

É exigência epistêmica que uma hipótese seja submetida aos mais diversos testes contrários para corroborá-la ou para descarta-la, de modo a se buscar uma nova hipótese. No âmbito processual, estes testes são provas que podem corroborar ou refutar as pretensões do demandante ou as defesas do demandado, o que justificarão uma sentença de procedência ou improcedência. Ao diminuir o âmbito de abrangência destas provas, estão sendo reduzidos os testes aos quais serão submetidas as alegações do autor ou do réu, prejudicando a busca da verdade.

${ }^{16}$ FÉRRER-BELTRAN, Jordi. op. cit. p. 80.

${ }^{17}$ Idem, p. 82. 
Revista Eletrônica de Direito Processual - REDP.

Rio de Janeiro. Ano 16. Volume 23. Número 1. Janeiro a Abril de 2022

Periódico Quadrimestral da Pós-Graduação Stricto Sensu em Direito Processual da UERJ

Patrono: José Carlos Barbosa Moreira (in mem.). ISSN 1982-7636. pp. 1160-1187

www.redp.uerj.br

Como segundo elemento, tem-se que a prova deverá ser produzida no âmbito do processo. As provas a fundamentarem o pedido ou a defesa devem estar sujeitas ao contraditório, permitindo à parte contrária que a refute, aponte ilegalidades ou mesmo a falta de verdade da prova. A produção da prova, portanto, deve "maximizar a participação das partes, mediante o princípio do contraditório, dando em todos os momentos a cada uma das partes a oportunidade de contraprovar o alegado pela parte contrária."18

O terceiro elemento é o direito a uma valoração racional das provas. De nada adiante que haja uma ampla aceitação das provas, que estas sejam submetidas ao contraditório, que as partes possam sempre contrapor-se ao alegado e provado pela parte contrária, se não houver sindicabilidade sobre sua valoração. Não basta que o juiz afirme que levou em consideração ou que conheceu todas as provas; deve deixar claro que sua decisão foi baseada nas provas, que elas foram suficientes (ou não foram) para comprovar o alegado e, por isso, decidiu de tal forma.

A doutrina sempre se preocupou em traçar meios de verificação sobre a valoração probatória. Neste ponto, estabelecem-se os sistemas de valoração de prova, sendo de se mencionar o sistema de provas tarifada, da íntima convicção, sistema do livre convencimento motivado e o da persuasão racional.

O sistema de provas tarifado, até hoje adotado em alguns procedimentos no direito brasileiro (como visto, o mandado de segurança admite somente as provas documentais) é um sistema de baixa inclusão, excluindo qualquer meio de provar o alegado que não aquele(s) especificamente(s) previsto(s) pela lei. Trata-se de uma escolha política do legislador de se entender que só se encontra provado um fato por um (ou alguns) determinado meio de prova, excluindo-se os demais, por mais especiais que sejam.

O sistema de íntima convicção prevê que o juiz deve valorar as provas produzidas pelas partes de acordo com sua própria experiência, com sua própria percepção do caso e das provas produzidas, podendo, livremente, optar por uma delas, sem fundamentação ou explanar, racionalmente, o porquê de uma prova ser mais apta à condução da verdade do que outra. Trata-

${ }^{18}$ FÉRRER-BELTRAN Jordi. op. cit. p. 84. 
Revista Eletrônica de Direito Processual - REDP.

Rio de Janeiro. Ano 16. Volume 23. Número 1. Janeiro a Abril de 2022

Periódico Quadrimestral da Pós-Graduação Stricto Sensu em Direito Processual da UERJ

Patrono: José Carlos Barbosa Moreira (in mem.). ISSN 1982-7636. pp. 1160-1187

www.redp.uerj.br

se de um sistema que, claramente, foge à racionalidade e, por isso, não tem mais valia nos sistemas jurídicos modernos.

O sistema do livre convencimento motivado, adotado no $\mathrm{CPC} / 73$, apontava que o juiz poderia "livremente" decidir de acordo com as provas produzidas. O advérbio "livremente", todavia, era entendido de forma equivocada pois, como lembram Fredie Didier Jr., Paula Braga e Rafael de Oliveira “a valoração da prova pelo juiz não é livre: há uma série de limitações, conforme examinado. Além disso, o adjetivo "livre" era mal compreendido, como se o juiz pudesse valorar a prova como bem entendesse."19

Por derradeiro, adota-se o sistema de persuasão racional que determinam que as provas não detém um valor apriorístico, devendo o juiz considerá-las conforme circunstancias específicas, como verossimilhança das alegações (especialmente no caso de testemunhas), probabilidade de seu acontecimento (o juiz não deve dar um grande peso para uma testemunha que afirma ter sido abduzida por extraterrestes, por exemplo), critérios científicos, dentre outros.

Apesar destes sistemas buscarem uma maior ou menor racionalidade na valoração das provas e, desta forma, admitir um maior controle sobre este processo decisório, não resta exposto qual o critério utilizado pelo magistrado para considerar que um fato está ou não provado ou, pelo menos, que está ou não está suficientemente comprovado a ponto de levar a uma sentença de procedência ou improcedência. Assim, deve-se perguntar: será possível realizar um controle dos parâmetros lógico-racionais utilizados pelo juiz ao valorar uma prova, ou não existem parâmetros racionais, devendo-se confiar puramente na reapreciação do fato pela instância superior, nas hipóteses em que admissível o recurso? Danilo Kjnik resume o dilema enfrentado:

Nesse sentido, se nos debruçarmos sobre a teoria estabelecida a respeito do princípio da persuasão racional - a começar por sua definição doutrinária observaremos, de pronto, um hiato inaceitável. Sua formulação clássica postula que a 'convicção está na consciência formada pelas provas, não arbitrária e sem peias, e sim, condicionada a regras jurídicas, a regras de lógica jurídica, a regras de experiência, tanto que o juiz deve mencionar nas sentenças os motivos que a formaram. (...) Há liberdade no sentido de que o juiz aprecia

${ }^{19}$ DIDIER Jr., Fredie, BRAGA, Paula Sarno, OLIVEIRA, Rafael Alexandria. Curso de Direito Processual Civil: Teoria da prova, Direito probatório, Decisão, Precedente, Coisa julgada e Tutela provisória. Volume 2. 13 ed. Salvador: Juspodivm, 2018. p. 121. 
Revista Eletrônica de Direito Processual - REDP.

Rio de Janeiro. Ano 16. Volume 23. Número 1. Janeiro a Abril de 2022

Periódico Quadrimestral da Pós-Graduação Stricto Sensu em Direito Processual da UERJ

Patrono: José Carlos Barbosa Moreira (in mem.). ISSN 1982-7636. pp. 1160-1187

www.redp.uerj.br

as provas livremente, uma vez que na apreciação não se afaste dos fatos estabelecidos, das provas colhidas, das regras científicas, regras jurídicas, regras de lógica, regras de experiência.' Ora, a partir desta compreensão, deveriam necessariamente existir 'controles', 'modelos de constatação', 'standards jurídicos' ou 'instrumentos' capazes de evitar que a discricionariedade judicial, agudizada neste dedicado setor da experiência processual, se viesse a traduzir em arbítrio. ${ }^{20}$

Assim, são estabelecidos métodos de controle - standards - para a valoração da prova, permitindo um controle mais apurado sobre o processo de formação da convicção do magistrado, permitindo haver critérios de controle sobre quando um fato é considerado ou não é considerado provado. Os standards - conforme detalharemos em capítulo posterior - não podem ser absolutamente rígidos, fechados, permitindo certa flexibilização, por sua própria natureza. Um conhecido standard probatório estadunidense utilizado para condenações criminais, que exige a prova do fato beyond any reasonable doubt (além de qualquer dúvida razoável) exige uma prova além de qualquer dúvida razoável, não havendo absoluta precisão o que seja “além da dúvida razoável”. Apesar da inexistência da objetividade completa, é inegável a maior possibilidade de controle da valoração da prova.

Como quarto e último elemento inerente ao direito à prova está o dever de motivação das decisões. ${ }^{21} \mathrm{O}$ dever de motivação é uma consequência lógica das etapas anteriores - seleção das provas a serem apresentadas, apresentação em processo sob o pálio do contraditório e critérios de valoração - sendo a exteriorização do processo de formação da decisão pelo magistrado, conforme as provas produzidas. O dever de motivação das decisões judiciais não é apenas um dever constitucionalmente previsto (art. 93, IX, Constituição da República Federativa do Brasil de 1988, doravante grafada somente como CRFB/88), mas uma necessidade lógica de um sistema que se pretende pautar pela racionalidade.

Por meio da fundamentação de suas decisões, o juiz explica o iter percorrido para a formação de sua convicção, submetendo suas hipóteses (que são exteriorizadas em decisões judiciais) à corroboração ou refutação pelas partes e pelos órgãos competentes para julgarem

20 KNIJIK, Danilo. Os “standards" do convencimento judicial: paradigmas para o seu possível controle. Disponível em:<http://www.abdpc.org.br/abdpc/artigos/danilo\%20knijnik\%20-\%20formatado.pdf>. Acesso em: 20 mar.2021.

${ }^{21}$ FÉRRER-BELTRAN, Jordi. op. cit. p. 85. 
Revista Eletrônica de Direito Processual - REDP.

Rio de Janeiro. Ano 16. Volume 23. Número 1. Janeiro a Abril de 2022

Periódico Quadrimestral da Pós-Graduação Stricto Sensu em Direito Processual da UERJ

Patrono: José Carlos Barbosa Moreira (in mem.). ISSN 1982-7636. pp. 1160-1187

www.redp.uerj.br

recursos. Não houvesse uma explicitação de como a decisão foi construída, quais provas foram valoradas e como, não haveria condições de serem testadas as hipóteses (decisões judiciais), o que acabaria por tornar o sistema judicial como sistema de "um homem só", inexistindo razão para um escalonamento hierárquico dos tribunais, com competências recursais ou, se estes existissem, apenas reavaliariam as decisões tomadas pelos juízos de grau inferior, sem qualquer apego à racionalidade da decisão tomada. Seria um sistema em que "duas decisões valeriam mais do que uma", independentemente da qualidade destas.

\subsection{O papel epistemológico dos standards probatórios}

Enquanto o Direito busca, constantemente, pelo alcance da verdade, é necessário que se tenha parâmetros para que seja determinada se a verdade foi alcançada, em decorrência das provas apresentadas ao juízo. Enquanto já foram apresentados critérios para que sejam especificadas quais provas devem ser apresentadas frente aos fatos apresentados e debatidos e, em segundo plano, a possibilidade de serem valoradas as provas apresentadas, há de se perquirir critérios para se estabelecer em que ponto essa busca deve ser cessada, entendendo-se que a verdade possível foi alcançada e qual seja esta verdade.

Os standards probatórios ou a quantificação das provas ou o quantum of proof servem de mecanismos para se emprestar racionalidade ao processo subjetivo do magistrado de se determinar a verdade, bem como objetiva-lo, tornando-o apto de ser mensurado sob um aspecto externo, seja pelas partes envolvidas, seja em eventual recurso da decisão.

Os standards de prova traduzem também a maior ou menor exigência de um grau de certeza sobre os fatos para que sejam providos ou improvidos os pedidos formulados pelo autor ou as exceções (lato sensu) opostas pelo demandado. Assim, é comum que a exigência para a condenação no âmbito penal seja mais acentuada do que no âmbito do processo civil, o que fez alguns autores apontarem, inclusive, que seria buscada a verdade material no campo penal e "somente" a "verdade formal”, no âmbito cível. Esta diferenciação, conforme se apontou, não tem qualquer razão, sendo inatingível - quiçá inexistente - uma verdade absoluta, sendo 
Revista Eletrônica de Direito Processual - REDP.

Rio de Janeiro. Ano 16. Volume 23. Número 1. Janeiro a Abril de 2022

Periódico Quadrimestral da Pós-Graduação Stricto Sensu em Direito Processual da UERJ

Patrono: José Carlos Barbosa Moreira (in mem.). ISSN 1982-7636. pp. 1160-1187

www.redp.uerj.br

necessário se alcançar a verdade processual (verdade "possível”) no âmbito do processo, sendo o standard maior ou menor a depender do bem tutelado no processo.

Sendo a verdade um valor importante a ser buscado e tutelado no processo ${ }^{22}$, deve-se analisar em que peso o procedimento probatório será suficiente para que seja alcançada esta verdade e, no tocante aos parâmetros probatórios, em qual momento esta poderá considerar-se demonstrada no processo e apta a fundamentar uma decisão judicial. Marcella Alves Mascarenhas Nardelli e Fabiana Alves Mascarenhas resumem o problema, apontando que:

A subjetividade do standard implica no afastamento do processo ao fim almejado da busca da verdade em seu ideal de correspondência, ficando muito mais próximo, ao contrário, das concepções subjetivas da verdade, aos quais consideram a formação do convencimento do julgador como objetivo primordial do processo. ${ }^{23}$

Desta forma, é imprescindível a colocação de balizas "extra epistêmicas", ou seja, balizas políticas e/ou jurídicas que consistirão em parâmetros objetivamente verificáveis sobre o suficiente alcance da verdade em um processo. Esta objetividade, contudo, não é absoluta, uma vez que os próprios standards possuem certo grau de subjetividade, permitindo uma certa flexibilização a depender do caso. O que é importante (e necessário) é a diminuição do aspecto de subjetividade, permitindo um maior controle, quer por razões epistemológicas, quer por razões jurídicas.

Para que sejam estabelecidos standards probatórios, é necessário, em primeiro lugar, se socorrer de critérios relativos à capacidade de fundamentação dos fatos apresentados com base nas provas apresentadas em juízo, especialmente partindo-se de um critério de probabilidade das mesmas (e não de certeza), aptas a formar o convencimento judicial.

Estes critérios são extraídos do próprio substrato processual e colocados de frente com as exigências legais para concessão ou não de um pedido. Veja-se, como exemplo, o artigo 300,

\footnotetext{
${ }^{22}$ É de se perceber que a verdade é um valor tido como objetivo no processo, mas também é protegido por ele. O Código de Processo Civil elenca como um dos deveres da parte a exposição dos fatos em juízo conforme a verdade (artigo 77, I) e considera como litigante de má-fé a parte que altera a verdade dos fatos (art. 80, II)

${ }^{23}$ NARDELLI, Marcella Alves Mascarenhas, MASCARENHAS, Fabiana Alves. Os standards probatórios como métrica da verdade: Em busca de parâmetros objetivos para a racionalização das decisões sobre os fatos. In Revista Del Instituto Colombiano de Derecho Procesal. Pp. 45-66. Disponível em: < http://publicacionesicdp.com/index.php/Revistas-icdp/article/view/425/0>. Acesso em: 22 mar. 2021. p. 57.
} 
Revista Eletrônica de Direito Processual - REDP.

Rio de Janeiro. Ano 16. Volume 23. Número 1. Janeiro a Abril de 2022

Periódico Quadrimestral da Pós-Graduação Stricto Sensu em Direito Processual da UERJ

Patrono: José Carlos Barbosa Moreira (in mem.). ISSN 1982-7636. pp. 1160-1187

www.redp.uerj.br

do Código de Processo Civil, que elenca como um dos requisitos para a concessão da tutela de urgência a "probabilidade do direito". Este critério dependerá dos fatos apresentados e das provas carreadas aos autos que exporão ao juiz uma maior ou menor probabilidade de conformação da exposição fática do demandante com as provas e contraprovas apresentadas. Se houver uma probabilidade de conformação dos fatos com o que fora demonstrado, a concessão da tutela provisória estará fundamentada.

O que se toma, então, como "probabilidade do direito"? A probabilidade, no Direito, deve ser entendida como aquela probabilidade "lógica", traduzida por Popper como "proximidade lógica de enunciados" 24 . Essa proximidade lógica recorre aos conceitos de deduzibilidade e compatibilidade. Assim, dado um enunciado E, tem-se um resultado R. Se, sempre que ocorrer um enunciado E, ocorre um resultado não-R, tem-se um grau de compatibilidade 0 e, portanto, é altamente improvável aquela alegação. Por outro lado, se sempre que ocorre um enunciado $\mathrm{E}$, tem-se um resultado $\mathrm{R}$, será altamente provável aquele enunciado.

Por evidente, que entre estes dois extremos - sempre que E, tem-se R ou sempre que E, tem-se não-R - há infindáveis variações, devendo a experiência conduzir a algo de maior ou menor probabilidade, de modo a se ter a compatibilidade com a requerida "probabilidade do direito", prevista no artigo 300, do CPC.

Este critério não zera a subjetividade daquele que tomará as decisões, mas, pelo menos, torna o processo decisório mais controlável e objetivo. A falibilidade da construção do raciocínio sobre o qual se baseou a decisão será mais facilmente controlável se os parâmetros forem objetivamente expostos e, portanto, sindicáveis.

Como segundo requisito para a formação de um parâmetro de prova, tem-se que "os critérios utilizados no standard probatório devem cumprir a função de estabelecer um patamar que seja o mais preciso possível, a partir do qual uma hipótese fática pode ser considerada" ${ }^{25}$.

Trata-se de uma exigência da própria busca pela verdade, sendo necessário a formulação de testes para sujeitar uma hipótese à sua comprovação ou refutação. É evidente que no âmbito

\footnotetext{
${ }^{24}$ POPPER, Karl. op. cit. p. 89

${ }^{25}$ FÉRRER-BELTRAN, Jordi. op. cit. p. 251.
} 
Revista Eletrônica de Direito Processual - REDP.

Rio de Janeiro. Ano 16. Volume 23. Número 1. Janeiro a Abril de 2022

Periódico Quadrimestral da Pós-Graduação Stricto Sensu em Direito Processual da UERJ

Patrono: José Carlos Barbosa Moreira (in mem.). ISSN 1982-7636. pp. 1160-1187

www.redp.uerj.br

processual, o número de testes que devem se colocar sobre uma hipótese são limitados por critérios jurídicos ou políticos. Assim, desde o momento das escolhas das provas especialmente em procedimentos que adotam o critério de prova legal, como ocorre no mandado de segurança - ao momento de exclusão de provas (por sua impertinência ou ilegalidade, por exemplo) até a fatores como duração do processo ou custos de produção de uma prova específica, tem-se limitações sistêmicas à busca pela verdade que impactarão na formulação do standard. É por isso que uma grande quantidade dos procedimentos que adotam critérios de prova legal, o fazem, pois permitem que as partes adotem outro procedimento - este, com maior possibilidade de escolha de provas a serem produzidas - para buscar seus direitos. São exemplos o mandado de segurança que, apesar de exigir apenas a prova documental, não se exclui da parte a possibilidade de buscar tutela de seu direito por via do procedimento comum; da mesma forma, a ação monitória que, a despeito de exigir somente prova documental ou, quando muito, prova documentada, não retira da parte a possibilidade de a parte socorrer-se ao procedimento comum.

Por derradeiro, tem-se que o grau de probabilidade lógica exigido para a formulação de decisão não será um valor matemático, mas de probabilidade lógica, erigida de critérios qualitativos e de experiência dos magistrados.

A compreensão dos standards probatórios passa pelo entendimento de sua função primordial; "distribuir o risco de erro entre as partes"26. Sendo a "verdade absoluta" inalcançável, o processo convive com probabilidade de erros nos resultados. A tolerância de erro será tanto menor quão mais importante for o bem jurídico tutelado; por outro lado, a tolerância ao erro será maior se estivermos frente a bens jurídicos de "menor monta", assim definidos pela própria sociedade.

O direito norte-americano, que muito utiliza a noção de standards probatórios, remetese, em geral, a três parâmetros distintos: evidence beyound any reasonable doubt (evidências além de qualquer dúvida razoável), preponderance of evidence (preponderância da evidência) e clear and convincing evidence (clara e convincente evidência) ${ }^{27}$. No primeiro, bastante utilizado no âmbito penal, tem-se que o critério para a condenação será a apresentação de prova para além

${ }^{26}$ FÉRRER-BELTRAN, Jordi. op. cit. p. 253

${ }^{27}$ NARDELLI, Marcella Alves Mascarenhas, MASCARENHAS, Fabiana Alves. op. cit. p. 57 
Revista Eletrônica de Direito Processual - REDP.

Rio de Janeiro. Ano 16. Volume 23. Número 1. Janeiro a Abril de 2022

Periódico Quadrimestral da Pós-Graduação Stricto Sensu em Direito Processual da UERJ

Patrono: José Carlos Barbosa Moreira (in mem.). ISSN 1982-7636. pp. 1160-1187

www.redp.uerj.br

de qualquer dúvida razoável, elevando-se o sarrafo da exigência probatória; na segunda, utilizada no âmbito cível, distribui-se de modo razoavelmente igual o risco de erro, sendo suficiente uma preponderância da evidência, independentemente do grau de preponderância. No último, também utilizado nos processos cíveis, tem-se um critério mais rigoroso para a avaliação da prova.

Resta nítida a tolerância com o erro, denotando, mais uma vez, a impossibilidade de se alcançar uma verdade material. Tome-se como exemplo o processo penal, que tem como standard a prova além de qualquer dúvida razoável. Neste, o padrão de erro é claro: é mais aceitável absolver um criminoso com base em provas com baixa probabilidade de verdade, do que condenar um inocente, face ao mesmo tipo de prova. $\mathrm{O}$ erro ocorre em ambas as situações - condenação do inocente ou absolvição do culpado; cabe à sociedade optar por qual será o erro com o qual aceitará conviver.

Estes não são os únicos standards probatórios existentes. O direito brasileiro os adota apesar de não usar essa nomenclatura - há algum tempo, como ocorre no mandado de segurança. Assim, ao se exigir o "direito líquido e certo" para a concessão do writ, resta evidente que não se exige "direito líquido e certo", que os "fatos que, por essa razão, deverão ser provados de maneira incontestável por prova documental"28. Apresenta-se, assim, duas limitações epistemológicas nesta ação de natureza constitucional: de primeiro, restringe-se de maneira significativa o aporte probatório, aceitando-se somente a prova documental (ou, quando muito, documentada) para a comprovação dos fatos alegados; em segundo plano, aumenta-se o padrão probatório, exigindo-se uma alta probabilidade (ou uma "certeza incontestável") para a concessão do pedido formulado no writ.

É de se perceber que a principal função do standard não é a busca da verdade, mas fornecer um padrão minimamente objetivo para que seja considerada (ou não) alcançada a verdade, de modo a se conceder ou negar, com base em critérios objetivamente controláveis, os pedidos formulados pelas partes no processo. Conforme apontam STRECK, RAATZ e

\footnotetext{
${ }^{28}$ NEVES, Daniel Amorim Assumpção. Ações Constitucionais. 4 ed. Salvador: Juspodivm, 2018. p. 174.
} 
Revista Eletrônica de Direito Processual - REDP.

Rio de Janeiro. Ano 16. Volume 23. Número 1. Janeiro a Abril de 2022

Periódico Quadrimestral da Pós-Graduação Stricto Sensu em Direito Processual da UERJ

Patrono: José Carlos Barbosa Moreira (in mem.). ISSN 1982-7636. pp. 1160-1187

www.redp.uerj.br

DIETRICH $^{29}$, busca-se reforçar o controle sobre o ato de valorar a prova, contribuindo, por conseguinte, com a legitimação da decisão judicial e, de outro ponto, rompe com a busca incessante e irracional pela "verdade absoluta", que mais atrapalha do que contribui para o desenrolar do processo.

\section{A PROVA NO MANDADO DE SEGURANÇA}

O mandado de segurança é assegurado pela CRFB/88, em seu artigo $5^{\circ}$, LXIX, dispondo que "conceder-se-á mandado de segurança para proteger direito líquido e certo, não amparado por habeas corpus ou habeas data, quando o responsável pela ilegalidade ou abuso de poder for autoridade pública ou agente de pessoa jurídica no exercício de atribuições do poder público”.

Apesar de não ser objeto do presente estudo a análise do histórico do mandado de segurança, tem-se esta ação como tipicamente brasileira, derivada da "crise que produziu a revisão da 'doutrina brasileira do habeas corpus, com a reforma constitucional de 1926, que alterou o $\S 22$ do art. 72, associando de forma expressa aquela ação à 'prisão ou constrangimento ilegal ",30, o que impôs a criação de uma outra garantia constitucional destinada a reparar lesões, por parte de agentes públicos ou seus delegatários, a direitos individuais que não o direito de liberdade. Esta natureza residual do mandado de segurança é vista de forma expressa na redação da atual CRFB/88 que o coloca como cabível quando não for possível a impetração de habeas corpus ou haheas data.

Coube à Lei 12.016/09 revogar expressamente a Lei 1.533/1951, que regulava este writ constitucional, adaptando o procedimento à nova realidade constitucional, em especial tratando de forma expressa do mandado de segurança coletivo, regulamentando o artigo $5^{\circ}$, LXX, CRFB/88.

29 STRECK, Lenio Luiz, RAATZ, Igor, DIETRICH, William Gale. Sobre um possível diálogo entre a crítica hermenêutica e a teoria dos standards probatórios: notas sobre a valoração probatória em tempos de intersubjetividade. In Revista Novos Estudos Jurídicos. Vol. 22. N. 2. Mai-ago. 2017. Disponível em:< https://siaiap32.univali.br/seer/index.php/nej/article/view/10981>. Acesso em: 23 mar. 2021. p. 403.

30 MENDES, Gilmar Ferreira, BRANCO, Paulo Gustavo Gonet. Curso de Direito Constitucional. 13 ed. São Paulo: Saraiva, 2018. p. 459. 
Revista Eletrônica de Direito Processual - REDP.

Rio de Janeiro. Ano 16. Volume 23. Número 1. Janeiro a Abril de 2022

Periódico Quadrimestral da Pós-Graduação Stricto Sensu em Direito Processual da UERJ

Patrono: José Carlos Barbosa Moreira (in mem.). ISSN 1982-7636. pp. 1160-1187

www.redp.uerj.br

No tocante ao cabimento, o artigo $1^{031}$ da Lei do mandado de segurança basicamente reproduz o texto constitucional. O dispositivo legal repetiu equívoco redacional replicado anteriormente; o direito, em verdade, sempre será líquido e certo. Ou o sujeito tem direito à prestação prevista por lei, ou não a tem. O que deve ser inconteste no mandado de segurança é a prova a ser apresentada ${ }^{32}$, dando ao julgador um grau elevado de probabilidade da verdade no processo. Utilizando-se standards probatórios já conhecidos, requer-se, para a concessão do pedido em mandado de segurança, uma evidence beyond any reasonable doubt. Daniel Neves explica que:

A certeza e a liquidez, portanto, dizem respeito aos aspectos fáticos da pretensão, não sendo das mais felizes a consagrada expressão 'direito líquido e certo'. Conforme reiteradas decisões dos tribunais superiores, o direito protegido pelo mandado de segurança exige do impetrante prova préconstituída suficiente para convencer o juízo no tocante ao aspecto fático de sua pretensão. ${ }^{33}$

Em verdade, nem sempre será necessário perquirir a existência de aspectos fáticos no mandado de segurança, que devem ser "líquidos e certos". É comum, aliás, a interposição de mandados de segurança em que se busca tutelar aspectos puramente jurídicos, como, por exemplo, nos mandados de segurança impetrados contra denegações ou concessões de liminares. É inegável, por outro lado, que um número significativo de mandados de segurança impetrados necessita de uma verificação de aspectos fáticos, como, por exemplo, writs impetrados para nomeação em concursos públicos por preterição de candidatos, contra apreensão ilegal de mercadorias em alfândega, dentre outros. Nestes casos, é necessário que os aspectos fáticos estejam comprovados beyound any reasonable doubt (além de qualquer evidência razoável) e por meio de prova documental (ou, quando muito, documentada).

É de se perceber que a própria lei atentou-se em limitar os meios de prova que podem ser utilizados no procedimento. Em uma interpretação literal, vê-se que o artigo $6^{\circ}$ da Lei

\footnotetext{
${ }^{31}$ Art. $1^{\circ}$ - Conceder-se-á mandado de segurança para proteger direito líquido e certo, não amparado por habeas corpus ou habeas data, sempre que, ilegalmente ou com abuso de poder, qualquer pessoa física ou jurídica sofrer violação ou justo receio de sofrê-la por parte de autoridade, seja de que categoria for e sejam quais forem as funções que exerça.

${ }^{32}$ Veja, por exemplo, a Súmula 625/STF que dispõe: Controvérsia sobre matéria de direito não impede concessão de mandado de segurança.

${ }^{33}$ NEVES, Daniel Amorim Assumpção. op. cit. p. 174
} 
Revista Eletrônica de Direito Processual - REDP.

Rio de Janeiro. Ano 16. Volume 23. Número 1. Janeiro a Abril de 2022

Periódico Quadrimestral da Pós-Graduação Stricto Sensu em Direito Processual da UERJ

Patrono: José Carlos Barbosa Moreira (in mem.). ISSN 1982-7636. pp. 1160-1187

www.redp.uerj.br

12.016/09 reduz o segundo momento da produção probatória - o da valoração da prova - à análise da prova documental, adotando, portanto, um sistema de prova tarifada.

Uma análise sistemática da norma, contudo, nos leva um entendimento um pouco mais ampliado. De fato, a limitação epistemológica pretendida pela lei não tem relação com uma busca da verdade mais limitada, mas, ao contrário, com um procedimento mais sumarizado, evitando-se dilação probatória. Assim, qualquer meio de prova - desde que apresentada junto à petição inicial na forma de documento - poderá ser utilizada, o que nos leva à conclusão que a prova testemunhal ou pericial, por exemplo, podem ser utilizadas, desde que reduzidas a um documento e acostada à petição inicial.

A alta probabilidade dos aspectos fáticos no mandado de segurança, traduzida na expressão "direito líquido e certo" não é compatível com uma redução quase absoluta do aspecto epistemológico do processo, limitando a somente uma espécie de prova a conduzir o julgador à busca da verdade; ao contrário, busca-se, tão somente, um alto custo ou larga duração do processo, por meio de uma dilação probatória que acabaria pro ordinarizar o procedimento. Daniel Amorim aponta que (2018, p. 176):

No mandado de segurança, a exigência da produção de prova já na petição inicial, como foi visto, tem como causa a necessidade de comprovação prima facie de, ao menos, uma plausibilidade do direito líquido e certo e, em nenhum momento, é possível concluir que esse convencimento no espírito do juiz a respeito dos fatos só possa ser obtido por meio da prova documental. Qualquer meio de prova é apto a convencer o juiz da ocorrência ou da veracidade de fatos; somente não se admite, no mandado de segurança, a dilação probatória.

A limitação à prova no mandado de segurança, portanto, tem mais relação com a sumarização do procedimento do que, propriamente, com a busca da verdade pelo magistrado. Este continua com seu dever de busca pela verdade, podendo utilizar qualquer fonte cognitiva para formar seu convencimento; a lei apenas traz uma limitação temporal na produção da prova, evitando-se a dilação probatória e exigindo que toda a prova seja produzida com a petição inicial ou, no máximo, nela indicada, quando a prova estiver em repartição ou estabelecimento público $\left(\operatorname{art} .6^{\circ}, \S 1^{\circ}\right.$, Lei $\left.12.016 / 09\right)$

\subsection{Standard probatório no mandado de segurança}


Revista Eletrônica de Direito Processual - REDP.

Rio de Janeiro. Ano 16. Volume 23. Número 1. Janeiro a Abril de 2022

Periódico Quadrimestral da Pós-Graduação Stricto Sensu em Direito Processual da UERJ

Patrono: José Carlos Barbosa Moreira (in mem.). ISSN 1982-7636. pp. 1160-1187

www.redp.uerj.br

A exigência de padrões decisórios responde a uma exigência de objetividade e sindicabilidade no processo, evitando-se subjetivismos exacerbados no momento da construção da decisão no processo e permitindo um controle racional pelas demais partes e pelo próprio Poder Judiciário em recurso da decisão. Assim, privilegia-se o aspecto cognitivo do magistrado, de modo a não tornar uma decisão uma mera "segunda visão" sobre o mesmo fato, sem critérios para reforma, mas, antes de mais nada, de um "teste de verificação" sobre aspectos epistemológicos e jurídicos da decisão judicial.

A utilização deste quantum of proof no mandado de segurança deve partir, antes de mais nada, de uma exigência da própria lei que aponta ser necessária a apresentação de um "direito líquido e certo" - ou, conforme já se apontou no tópico anterior, que o aspecto fático de demanda seja comprovado com alta plausibilidade, uma vez que o direito, per si, sempre será "líquido e certo".

Para que sejam construídos (ou apresentados) os standards probatórios exigidos para a decisão no mandado de segurança, retornar-se-á aos requisitos metodológicos para formação de um padrão probatório, apontado no capítulo 2.3 deste estudo.

Em primeiro lugar, faz-se necessário perquirir os critérios relativos "à capacidade de justificação do acervo probatório sobre as conclusões probatórias estabelecidas"34. Com isso se requer, basicamente, que os critérios utilizados para a formação do convencimento do magistrado não sejam de pura convicção íntima, devendo ser objetivamente verificável. A racionalidade do processo exige que a verdade alcançada pelo magistrado possa ser submetida a testes de verificação, para refutá-la ou confirmá-la; estes testes são realizados por meio dos recursos em que, mais do que uma "loteria decisória", se reveste de uma necessária testabilidade, verificando graus de precisão e/ou falseabilidade da decisão judicial.

Em segundo lugar, os critérios apontados como standards devem ser critérios de uma verdade possível, não sendo exigida, por óbvio, que se alcance a verdade material. Essa limitação é importante não apenas para reduzir a utópica busca pela perfeição, mas, também,

\footnotetext{
${ }^{34}$ FÉRRER-BELTRAN, Jordi. op. cit.p. 250.
} 
Revista Eletrônica de Direito Processual - REDP.

Rio de Janeiro. Ano 16. Volume 23. Número 1. Janeiro a Abril de 2022

Periódico Quadrimestral da Pós-Graduação Stricto Sensu em Direito Processual da UERJ

Patrono: José Carlos Barbosa Moreira (in mem.). ISSN 1982-7636. pp. 1160-1187

www.redp.uerj.br

por estabelecer de forma intersubjetiva o limite exigido para a verificação dos fatos apresentados e comprovados em mandado de segurança.

Neste critério, a própria lei se preocupou em defini-lo, exigindo uma alta probabilidade para a concessão do mandado de segurança. A exigência desta alta probabilidade não fecha as portas para que, denegada a segurança sem que tenha sido comprovada a veracidade das alegações, o autor se socorra de vias ordinárias para reformular seu pedido, desta vez não apenas com um cabedal probatório mais amplo, mas, acima de tudo, com um padrão decisório menos exigente. Vale dizer: a diferença, em termos de provas, do mandado de segurança para os procedimentos comuns, não se situam somente nas provas permitidas mas, acima de tudo, no padrão decisório que, no mandado de segurança, é mais exigente (padrão mais elevado) e, no procedimento comum, o risco de erro é dividido de forma mais igualitária entre as partes, diminuindo-se, portanto, o standard probatório.

Como derradeiro requisito metodológico para a formação do standard probatório neste writ constitucional, tem-se que sua construção não depende de "números ou fórmulas quantitativas, mas sim de critérios qualitativos" ${ }^{\text {35. }}$.

Aqui é de se recorrer à fórmula estadunidense de evidence beyond any reasonable doubt, utilizada basicamente nos processos criminais naquele país. Apesar de seu uso em processos de natureza penal, nos parece que a exigência necessária para a condenação muito se assemelha à exigência requerida para a concessão da segurança.

A razão deste padrão decisório elevado não é tanto o bem jurídico tutelado, mas, antes de mais nada, a sumariedade do procedimento e, em especial, o fato de a decisão que denega a segurança não impedir que a parte busque a tutela jurisdicional por outros meios. Em outras palavras, mesmo que o magistrado entenda não ser caso de concessão do pedido formulado em mandado de segurança, é possível que a parte busque tutelar seu direito por ação de procedimento comum, em que terá ampla possibilidade de produção de prova e um menor standard probatório. Os aspectos para a formulação deste standard não são propriamente

\footnotetext{
${ }^{35}$ FÉRRER-BELTRAN, Jordi. op. cit. p. 252
} 
Revista Eletrônica de Direito Processual - REDP.

Rio de Janeiro. Ano 16. Volume 23. Número 1. Janeiro a Abril de 2022

Periódico Quadrimestral da Pós-Graduação Stricto Sensu em Direito Processual da UERJ

Patrono: José Carlos Barbosa Moreira (in mem.). ISSN 1982-7636. pp. 1160-1187

www.redp.uerj.br

epistemológicos, mas, sobretudo, políticos e jurídicos, ao se exigir um alto grau de certeza, quando se estiver em um procedimento sumarizado e sem possibilidade de dilação probatória.

\section{CONSIDERAÇÕES FINAIS}

O Direito tem como uma de suas finalidades principais a busca pela verdade. Esta busca se dá primacialmente por meio de processos, em que são formuladas alegações por parte do demandante e do demandado que, sujeitos à verificação probatória, permitem que o juiz decida concedendo ou denegando o pedido com base em sua convicção. A busca da verdade tem relação intrínseca com o papel de estimulante ou proibidor de condutas positivas ou negativas, de modo que só terá atingido o fim de regular as condutas se for aplicada precisamente a consequência normativa àquele que praticou o seu antecedente. Qualquer erro nesta relação levará a um descrédito e, por conseguinte, uma deslegitimação do sistema jurídico.

Essa busca da verdade no processo judicial já foi alvo de diversas teorizações, sendo uma de suas principais preocupações que a verdade alcançada no processo seja o mais próximo possível da verdade real e, ainda, que haja uma verificação dos critérios utilizados para que fosse alcançada esta verdade. Sob o ponto de vista epistemológico, as principais discussões são "que verdade?" e "como se alcançar a verdade?" no âmbito do processo.

A despeito da evolução de alguns sistemas de valoração de prova, a exigência de um processo racional requer, como consequência, um sistema também racional de valoração de provas. O critério da íntima convicção e do livre convencimento dão lugar ao critério da persuasão racional, em que se faz necessário sujeitar a critérios de testes epistemológicos todos os momentos de formação da prova, ou seja, desde a escolha dos aspectos fáticos a serem provados, à valoração da prova e ao próprio julgamento sobre as provas. Em todos estes critérios, é necessário ser explícito sobre quais métodos (racionais) são utilizados e sujeita-los a testes de falseabilidade, para aproximar a verdade processual com a verdade real.

Enquanto os dois primeiros passos são objetos de diversas normas no âmbito do processo judicial - seja no processo de natureza penal ou não penal - a última etapa, vale dizer, a etapa do julgamento sobre as provas ainda não mostrou critérios de verificação intersubjetivas, em 
Revista Eletrônica de Direito Processual - REDP.

Rio de Janeiro. Ano 16. Volume 23. Número 1. Janeiro a Abril de 2022

Periódico Quadrimestral da Pós-Graduação Stricto Sensu em Direito Processual da UERJ

Patrono: José Carlos Barbosa Moreira (in mem.). ISSN 1982-7636. pp. 1160-1187

www.redp.uerj.br

que se desnudam os aspectos do raciocínio do magistrado, colocando-os à prova pelas partes e pelo próprio sistema jurídico.

Com a finalidade de aumentar a objetividade deste processo cognitivo, são apontados os standards probatórios que são tidos como padrões decisórios necessários para que o juiz conceda ou não os pedidos formulados em processos judiciais, de acordo com as provas apresentadas. Em outras palavras, os standards podem ser comparados com o sarrafo que o atleta utiliza para saltar em provas de atletismo; quanto mais alto o sarrafo, mais difícil o salto. No âmbito judicial, quanto mais alto o sarrafo, maior a exigência de convencimento e, assim, deve ser maior a probabilidade que os fatos narrados, com as provas apresentadas, sejam compatíveis com a "verdade material".

Os standards probatórios são exigências epistemológicas construídas por critérios políticos ou jurídicos, de acordo com o bem jurídico tutelado, duração e custo do processo e outros aspectos que a sociedade e o direito elencam como importantes. Assim, apesar de ser um instrumento epistemológico, é construído a partir de fatores "não-epistemológicos", mostrando o aspecto sistêmico do direito.

A par da existência de vários standards apontados pela doutrina, utilizou-se aqui os três standars mais "tradicionais": evidence beyound any reasonable doubt, preponderance of evidence e clear and convincing evidence. Estes standars são utilizados no direito estadunidense no âmbito dos processos criminais e dos processos cíveis, na sequência.

No tocante ao mandado de segurança, o artigo $6^{\circ}$ da Lei 12.016/09 não deve ser interpretado literalmente, de modo a serem admitidas somente provas documentais. Ao contrário, a exigência do mandado de segurança de que os aspectos fáticos sejam comprovados, sem necessidade de dilação probatória, não reduz a possibilidade de o juiz formar seu convencimento por parte de qualquer meio de prova, mas, somente, impossibilita que as provas sejam produzidas durante o processo. Vale dizer, é possível a utilização de qualquer meio de prova para convencer o magistrado, desde que estas provas sejam documentadas e apresentadas junto à petição inicial.

O mandado de segurança, portanto, tem uma maior exigência não tanto no aspecto de quais provas devem ser utilizadas, mas, especialmente, no standard exigido para o 
Revista Eletrônica de Direito Processual - REDP.

Rio de Janeiro. Ano 16. Volume 23. Número 1. Janeiro a Abril de 2022

Periódico Quadrimestral da Pós-Graduação Stricto Sensu em Direito Processual da UERJ

Patrono: José Carlos Barbosa Moreira (in mem.). ISSN 1982-7636. pp. 1160-1187 www.redp.uerj.br

convencimento do magistrado. A exigência do "direito líquido e certo" remete, na verdade, à alta probabilidade da veracidade das alegações do impetrante, quando confrontadas com as provas apresentadas, elevando-se sobremaneira o padrão decisório à evidence beyond any reasonable doubt.

Essa exigência qualificada para a "verdade" no mandado de segurança não tem relação direta com o bem jurídico tutelado - posto que podem ser vários os bem jurídicos tutelados mas, sobretudo, com a sumarização do procedimento e, em especial, com a possibilidade de o demandante buscar a tutela de seus direitos, após ser-lhe negado o mandado de segurança, por meio das vias ordinárias. De fato, a não concessão do mandado de segurança não o impede de pleitear o mesmo direito por meio do procedimento comum (Lei 12.016, art. 19) em que haverá uma maior dilação probatória e, em especial, um menor standard, admitindo-se uma diluição mais igualitária dos riscos da verdade no processo.

\section{REFERÊNCIAS:}

DIDIER Jr., Fredie, BRAGA, Paula Sarno, OLIVEIRA, Rafael Alexandria. Curso de Direito Processual Civil: Teoria da prova, Direito probatório, Decisão, Precedente, Coisa julgada e Tutela provisória. Volume 2. 13 ed. Salvador: Juspodivm, 2018.

FÉRRER-BELTRAN, Jordi. Valoração racional da prova. Trad. Vitor de Paulo Ramos. Salvador: Juspodivm, 2021.

HESSEN, Johannes. Teoria do Conhecimento. Trad.: João Vergílio Gallerani Cuter. São Paulo: Martins Fontes, 2003.

KNIJIK, Danilo. Os “standards” do convencimento judicial: paradigmas para o seu possível controle.

Disponível em:<http://www.abdpc.org.br/abdpc/artigos/danilo\%20knijnik\%20\%20formatado.pdf>. Acesso em: 20 mar.2021.

POPPER, Karl. A Lógica da pesquisa científica. Trad. Leonidas Hegenberg e Octanny Silveira da Mota. Cultrix: São Paulo, 2008. 
Revista Eletrônica de Direito Processual - REDP.

Rio de Janeiro. Ano 16. Volume 23. Número 1. Janeiro a Abril de 2022

Periódico Quadrimestral da Pós-Graduação Stricto Sensu em Direito Processual da UERJ

Patrono: José Carlos Barbosa Moreira (in mem.). ISSN 1982-7636. pp. 1160-1187 www.redp.uerj.br

MARINONI, Luiz Guilherme, ARENHART, Sergio Cruz, MITIDIERO, Daniel. Curso de Processo Civil: Volume 2. 4 ed. São Paulo: Revista dos Tribunais, 2018.

MENDES, Gilmar Ferreira, BRANCO, Paulo Gustavo Gonet. Curso de Direito Constitucional. 13 ed. São Paulo: Saraiva, 2018.

NARDELLI, Marcella Alves Mascarenhas, MASCARENHAS, Fabiana Alves. Os standards probatórios como métrica da verdade: Em busca de parâmetros objetivos para a racionalização das decisões sobre os fatos. In Revista Del Instituto Colombiano de Derecho Procesal. Pp. 45-66. Disponível em: < http://publicacionesicdp.com/index.php/Revistas-icdp/article/view/425/0>. Acesso em: 22 mar. 2021.

NEVES, Daniel Amorim Assumpção. Ações Constitucionais. 4 ed. Salvador: Juspodivm, 2018. STRECK, Lenio Luiz, RAATZ, Igor, DIETRICH, William Gale. Sobre um possível diálogo entre a crítica hermenêutica e a teoria dos standards probatórios: notas sobre a valoração probatória em tempos de intersubjetividade. In Revista Novos Estudos Jurídicos. Vol. 22. 2. $2017 . \quad$ Mai-ago. Disponível em:< https://siaiap32.univali.br/seer/index.php/nej/article/view/10981>. Acesso em: 23 mar. 2021.

TARUFFO, Michele. La verdade en el proceso. Trad. Eugenia Ariano Deho. In Revista Derecho \& Sociedad 40. Pp. 239-248. Disponível em:< https://www.google.com/url?sa=t\&rct=j\&q=\&esrc=s\&source=web\&cd=\&ved=2ahUK Ewj_oaWR98HvAhWCJbkGHcQFDzUQFjAAegQIARAD\&url=http\%3A\%2F\%2Fre vistas.pucp.edu.pe\%2Findex.php\%2Fderechoysociedad\%2Farticle\%2Fdownload\%2F1 2804\%2F13361\%2F0\&usg=AOvVaw2Qxb7olXCCUcUIp9uu7q2T>. Acesso em: 19 mar. 2021. 